\title{
Inhibitory effect of eight Secondary Metabolites from conventional Medicinal Plants on COVID_19 Virus Protease by Molecular Docking Analysis
}

\author{
Narges Mohammadi ${ }^{1}$, Neda Shaghaghi ${ }^{1}$ \\ ${ }^{1}$ Faculty of Science, University of Maragheh, East Azarbaijan, Iran
}

\begin{abstract}
Due to the reported high ability of virulence of COVID_19 in recent months, several studies have been conducted to discover and introduce COVID_19 antiviral drugs. The results of numerous studies have shown that protease inhibitors, which make up the major part of plant derivatives can therefore be very effective in controlling virus-induced infection. The aim of this research is the bioinformatical study of COVID_19 inhibition by Secendary Metabolite of medicinal herbs. This is a descriptive-analytic study. In the present study, the structure of Secendary Metabolite and COVID_19 protease was received from the databases such as PubChem and Protein Data Bank (PDB). After that, Molecular Docking was performed by MVD(molegro virtual docker) software.The results are identified to have inhibitory activities against novel COVID-19 protease. Of these compounds, Curcumin has a stronger bond and high affinity with protease. Finally, with due attention to the high effectiveness function of plant compounds, we can conclude that these compounds may be considered as effectire COVID_19 antiprotease drugs.
\end{abstract}

Keywords: Coronavirus, Bioinformatic, Plant drug, Docking, Secendary Metabolite

\section{Introduction}

\section{Coronavirus}

Coronaviruses (scientific name: Coronaviruses) are a large family of viruses, ranging from the common cold virus to the more serious diseases such as SARS, MERS, and CWID. Their structure also has a typical RNA genome. People with concomitant illness and children with 
heart disease are at greater risk of developing coronavirus. Usually the severity of the cold that causes coronavirus is greater. Although corona viruses are more common in animals, seven of them affect the respiratory system of the human body. The structure of the virus consists of two layers; the core of the virus is the genetic material and the outer layer is the protein crown. Also on December 7, for the first time in Wuhan, Hubei Province, China, a new type of coronavirus was identified with a human epidemic after people contracted pneumonia and vaccines and treatments were not effective. By March 15, 2020, this new coronavirus has killed more than 4,000 people and more than 100,000 people have been confirmed in more than 100 countries. Although many efforts have been made to produce the vaccine, there is still no specific vaccine or antiviral drug for the prevention or treatment of coronavirus infections in general (Chen et al, 2020; Shaghaghi, 2020),

\section{Medicinal plants}

The international outlook for the drug organization has been changing rapidly lately. As the world's population is constantly aging, lifestyle-related illnesses and chronic illnesses have become more common, and more and more people are seeking to improve their quality of life, with a focus on disease prevention, The development of herbal remedies has focused on the treatment of viral diseases, aging, cancer, chronic diseases and lifestyle-related diseases. As a result, traditional medicine whose long-term safety and clinical effects have been approved for the treatment of previously mentioned diseases and herbal remedies based on traditional medicines are expected to grow. Significant. The consumption of medicinal plants in different countries is increasing day by day due to the proven effectiveness of many of these substances in scientific societies and its acceptance in most human societies. Due to the growing concern about the side effects of chemical drugs and the ineffectiveness of some of them for long-term use, the use of natural alternatives to or complementary therapies has received increasing attention. Herbal remedies are used as alternative therapies with fewer side effects and in some cases as the only effective treatment. The World Health Organization estimates that about 80 percent of people use herbal remedies. However, only a few plant species are studied for their therapeutic properties, mechanism of action, immunity and toxicity. Therefore, much research is being done on medicinal plants. In Iran, medicinal herbs are often used in traditional medicine; many of them have been studied for various therapies (Baell, 2016).

\section{Molecular docking}


Bioinformatics is one of the most important and innovative approaches to design and manufacture of new drugs. Due to the high cost of clinical and laboratory trials, the time consuming and the possibility of error, different bioinformatics techniques are nowadays used in the design of new drugs. Molecular docking, simulation, target point determination and chemical stability studies are the most important bioinformatics methods used in drug design. Molecular docking has a special place in the process of designing, evaluating and comparing new drugs. In this technique, one can examine the interactions of the molecules in the threedimensional space by considering the different states of the molecules and determine the factors involved in the more involved and important pharmacological interaction(Grinter \& Zou, 2014; Mukesh \& Rakesh, 2011). One of the novel therapeutic strategies for coronavirus infection other than the design and chemical synthesis of these drugs is to search for inhibitors of this enzyme among natural compounds in order to obtain drugs with the least side effects. So far, many studies have been carried out to identify and introduce anticoronavirus drugs with inhibitory effect, but the effects of herbal medicines have received little attention (Shaghaghi, 2020).

\section{Data collection}

This study was a descriptive-analytical one. In this study, the interactions of eight secondary metabolites from commonly used plants that have already been proven to have antiviral, antibacterial and anti-inflammatory effects are described in Table 1. In order to obtain their 2 and 3 dimensional structure, a database of Pubchem compounds was used. The complete protein protease database COVID_19 was used to access the protein database at www.pdb.org.

Table 1.Name and structure of the compounds studied

\begin{tabular}{|c|c|c|c|c|}
\hline No & Plant & $\begin{array}{c}\text { Scientific } \\
\text { Name }\end{array}$ & $\begin{array}{c}\text { Secondary } \\
\text { Metabolite }\end{array}$ & $\begin{array}{c}\text { 2D Structure of Secondary } \\
\text { Metabolite }\end{array}$ \\
\hline & & & & \\
1 & Garlic & Allium & Diallyl Disulfide & \\
& & sativum & & \\
\hline
\end{tabular}




\begin{tabular}{|c|c|c|c|c|}
\hline 2 & Turmeric & $\begin{array}{c}\text { Curcuma } \\
\text { longa }\end{array}$ & Curcumin & \\
\hline 3 & Pepper & Capsicum & capsaicin & \\
\hline 4 & Cardamom & Elettaria & Limonene & \\
\hline 5 & Pennyroyal & $\begin{array}{c}\text { Mentha } \\
\text { pulegium }\end{array}$ & Thymol & \\
\hline 6 & Liquorice & $\begin{array}{c}\text { Glycyrrhiza } \\
\text { glabra }\end{array}$ & Coumarin & \\
\hline 7 & $\begin{array}{l}\text { Hedge } \\
\text { Nettle }\end{array}$ & $\begin{array}{c}\text { Stachys } \\
\text { schtschegleevi }\end{array}$ & verbascoside & \\
\hline
\end{tabular}




\begin{tabular}{|c|c|c|c|c|}
\hline 8 & Tragacanth & $\begin{array}{l}\text { Astraglus } \\
\text { gossypinus }\end{array}$ & glucuronic acid & \\
\hline
\end{tabular}

\section{Molecular Docking}

In this study, the specific molecular docking software (MVD) was used to investigate the molecular interaction between drugs and protease enzyme. This software provides a threedimensional view of the interaction between compounds and the protease enzyme virus and the amino acids participating in the interaction. In the present study, all docking conditions including the interaction frequency, the study area of interaction, the protease enzyme and the rate of docking were considered to minimize error. During this molecular docking study, the number of interaction run is 10 , the diameter of interaction area 30 (angstrom) with the ability to investigate the hydrogen-electrostatic and van der Waals interactions in the total active site of the enzyme were compared and the results were compared.

\section{Results}

The results of this study indicate the strong interactions of drugs in the enzymatic flap conserved region. Among the interactions that occur in these regions are often van der Waals, the binding of three important amino acids due to their presence in the highly conserved region has an active site and a key role in enzymatic catalysis. The results of these compounds are summarized in Tables 2 and 3.

Table 2. The sum of the energies resulting from the interaction of terpenoids and protease enzymes

\begin{tabular}{llllll}
\hline No. & Compound name & Total Energy & Ester Bond & $\begin{array}{l}\text { Hydrogrn } \\
\text { Bond }\end{array}$ & $\begin{array}{l}\text { Electrostatic } \\
\text { Bond }\end{array}$ \\
\hline 1 & Diallyl Disulfide & -52 & -49 & 0 & 0 \\
2 & Curcumin & -127 & -109 & -14 & 0
\end{tabular}




\begin{tabular}{llllll}
3 & capsaicin & -107 & -95 & -6 & 0 \\
4 & Limonene & -54 & -55 & 0 & 0 \\
\hline 5 & Thymol & -55 & -56 & -2 & 0 \\
6 & Coumarin & -57 & -64 & -3 & 0 \\
7 & verbascoside & -95 & -99 & -5 & 0 \\
\hline 8 & glucuronic acid & -64 & -56 & -6 & 0 \\
\hline
\end{tabular}

Table 3.The amount of binding energy of protease amino acids to compounds.

\begin{tabular}{|c|c|c|c|c|c|c|c|c|c|c|c|c|c|c|c|c|}
\hline No & Amino Acid & $\begin{array}{l}\text { Ar } \\
\text { g }\end{array}$ & $\begin{array}{l}\text { As } \\
\text { n }\end{array}$ & $\begin{array}{l}\text { As } \\
\text { p }\end{array}$ & $\begin{array}{l}\text { As } \\
\text { p }\end{array}$ & $\begin{array}{l}\text { Cy } \\
\text { s }\end{array}$ & $\begin{array}{l}\text { Gl } \\
\mathbf{n}\end{array}$ & Gln & Ile & Ile & Phe & Phe & Ser & Thr & $\begin{array}{l}\text { Th } \\
\mathbf{r}\end{array}$ & Val \\
\hline & Residue & 105 & 151 & 153 & 295 & 156 & 107 & 110 & 106 & 152 & 8 & 294 & 158 & 111 & 292 & 104 \\
\hline 1 & Diallyl & & -11 & -6 & -0.4 & -0.4 & & -2 & & -5 & -1.8 & -12 & -1 & -0.6 & -1 & \\
\hline & Disulfide & & & & & & & & & & & & & & & \\
\hline 2 & Curcumin & -4 & -16 & -11 & -2 & -0.6 & -1 & -11 & -10 & -7 & -1.8 & -26 & -6 & -2 & -1 & -7 \\
\hline 3 & capsaicin & -8 & -11 & -9 & & & -9 & -11 & -16 & -2 & -0.3 & -14 & -3 & -0.6 & -0.6 & -6 \\
\hline 4 & Limonene & & -16 & -8 & -1 & -0.4 & & -1.3 & & -6 & -3 & -10 & -1 & -2.6 & -0.8 & \\
\hline 5 & Thymol & & -18 & -14 & & & & -0.3 & -0.7 & -5 & -0.8 & -6 & -6 & -0.4 & -1.3 & \\
\hline 6 & Coumarin & & -9 & -5 & -4 & & & -4 & & -3 & -5 & -21 & & -6 & -5 & \\
\hline 7 & $\begin{array}{l}\text { verbascosid } \\
\text { e }\end{array}$ & -0.3 & -13 & -0.4 & -6 & & -4 & -35 & & & -2 & -20 & -0.7 & -8 & -7 & -0.8 \\
\hline 8 & $\begin{array}{l}\text { glucuronic } \\
\text { acid }\end{array}$ & & -16 & -6 & -1 & & & -1 & -0.3 & -7 & -5 & -11 & -2 & -6 & -0.8 & \\
\hline
\end{tabular}



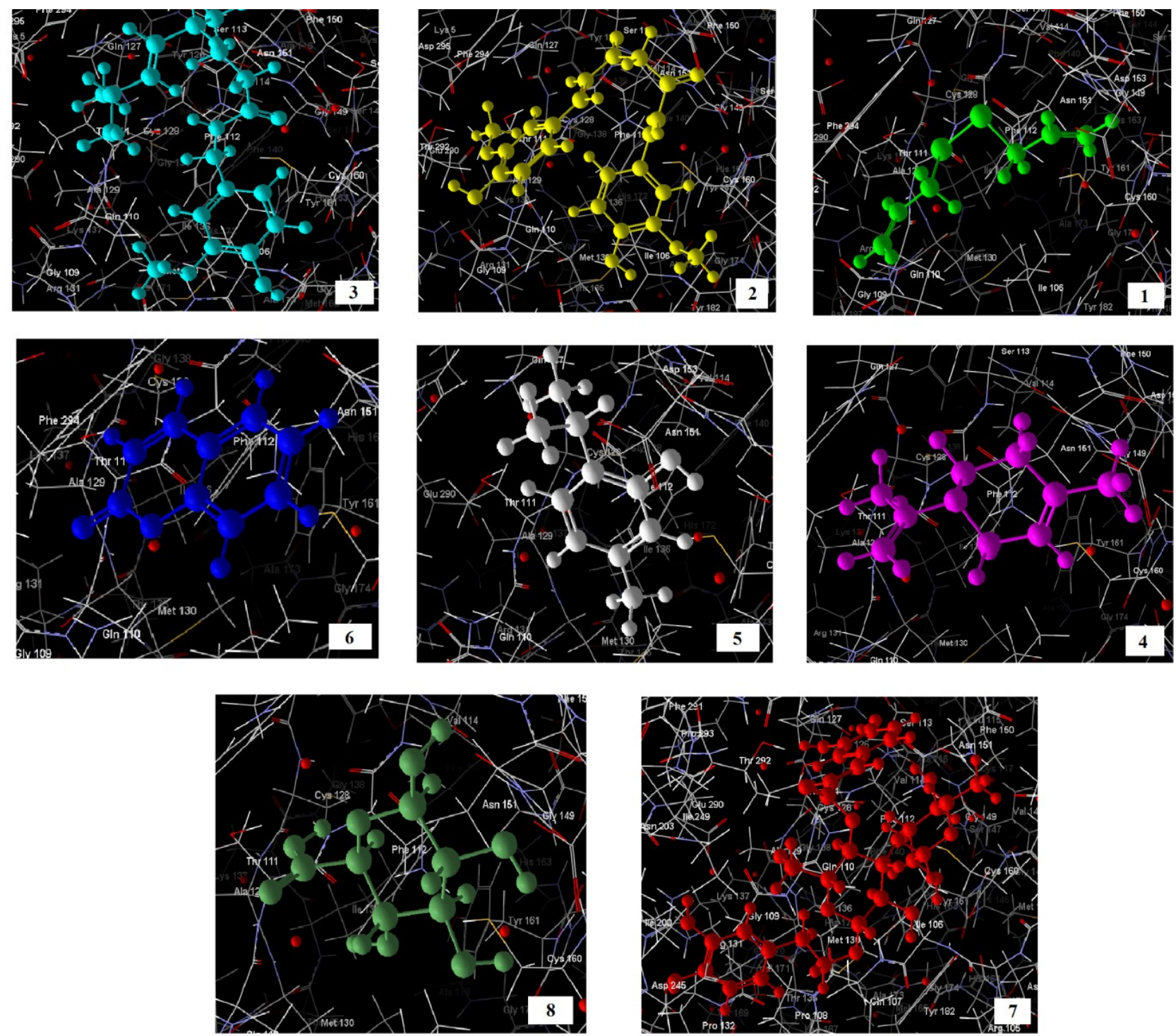

Figure 1.The interaction between terpene compounds in the active site of the protease enzyme virus: 1:Diallyl Disulfide 2:Curcumin 3:capsaicin 4:Limonene 5:Thymol 6:Coumarin 7:verbascoside 8:glucuronic acid 


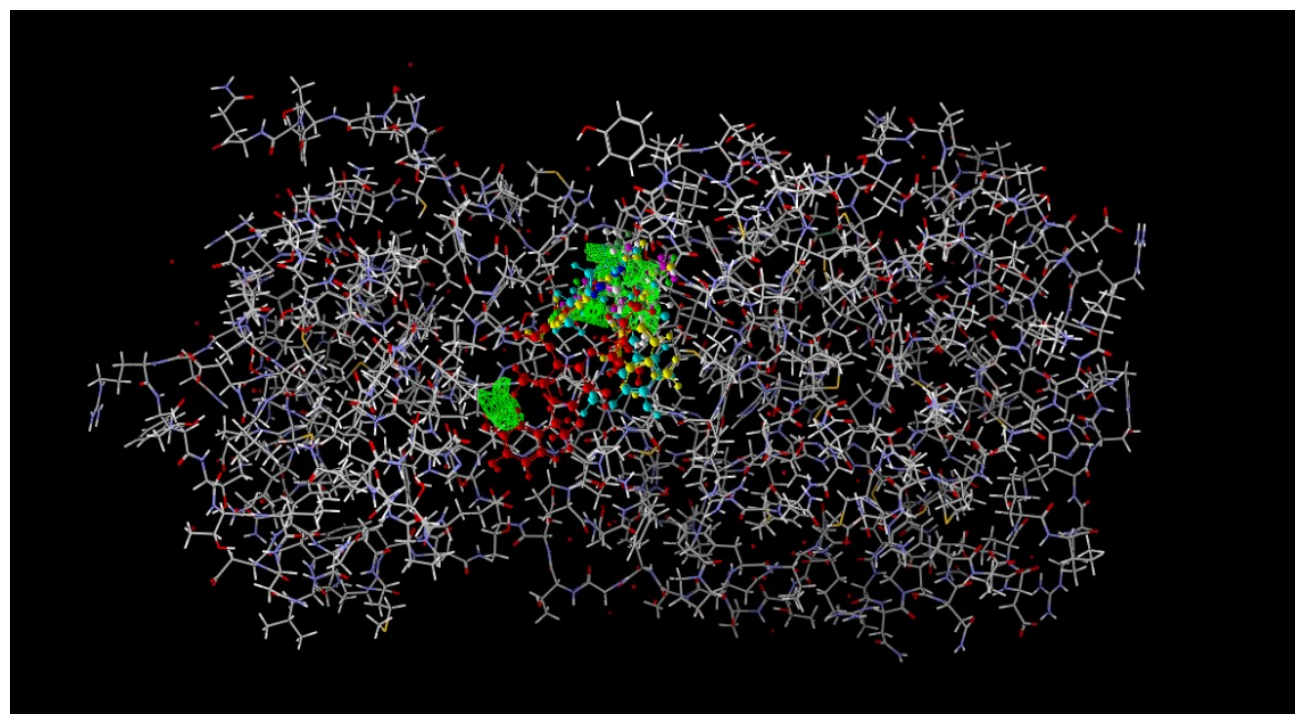

Figure 2. Interactions between compounds and COVID_19 protease are put into the active site of the protease virus

\section{Discuss}

The results of this study showed that the compounds studied can effectively inhibit the virus protease enzyme. These compounds can effectively inhibit these amino acids during the catalytic process by interacting with the key amino acids active site. Secondary metabolites are the ability of plants to process various organic molecules. Most of the secondary metabolites are used as medicines, chemicals, seasonings, antioxidants and essential oils. In this study we examined the secondary metabolites of 8 plants that have already proven their drug effects. Garlic is a natural antibiotic, strong antifungal and anti-virus, cures respiratory infections. The garlic-derived compound, dialloyl sulfide, is capable of eliminating the biofilms of this bacterium (biofilms are 1000 times more resistant to floating bacteria than antibiotics) (Lu et al, 2012). Curcumin is an active ingredient in turmeric spices and has antiinflammatory properties. Curcumin is a potent antioxidant. Turmeric's active ingredient, curcumin, has anti-inflammatory and analgesic effects similar to conventional painkillers. The anti-inflammatory effect of curcumin is comparable to the anti-inflammatory effect of steroidal and non-steroidal drugs with phenylbutazone. It inhibits the anti-inflammatory effect by inhibiting the synthesis of inflammatory prostaglandins (Menon \& Sudheer, 2007). Capsaicin or capsaicin is a chemical from the genus Capsicum. It is found in spicy peppers (green and red). Regular consumption of this vegetable in the diet reduces both the severity and duration of the cold. (In a kilo of pepper, there are 5 times the orange of the same weight 
as vitamin C). It also has disinfectant properties. Capsaicin in peppers, especially in common peppers, has a chemical composition that stimulates the immune system and helps the system attack invasive agents (Sricharoen et al., 2017). Cardamom contains two substances called limonene and cineol which have anti-cancer properties. Secondary compounds called limonoids have antiviral effects. Aglycones such as limonene and glucosides such as glucoside-limonene are examples of limonoids that also cause a bitter taste in citrus fruits (Vutakuri \& Somara, 2018). The essential oil of Pennyroyal contains about 50\% of thymol. Pennyroyal is useful for dealing with nausea, vomiting, gastrointestinal problems, flu, asthma, cough and pertussis. Due to the antimicrobial properties of extracts and essential oils of it, these products can be used as natural substitutes for antibiotics (da Silva Ramos et al., 2017). Liquorice is one of the herbs of the car and is less cultivated and cultivated. Coumarin is a by-product of secondary metabolism common in the root of this plant. Molecular structures of coumarin have numerous biological activities. These include the effects of antifungal, antibacterial, anti-AIDS, antimicrobial, antiviral, anti-malarial, anti-cancer, antiinflammatory, anticoagulant, antioxidant, and so on (Venugopala et al, 2013). Hedge Nettle that the plant is anti-inflammatory, antiseptic, antibacterial and antimicrobial. It is very effective in treating diseases such as sinusitis, asthma, rheumatism, colds, urinary tract infections and urinary incontinence and internal infections in women. This herb contains Verbascoside (Maleki-Dizaji et al, 2008). Tragacanth is a dried gum discharge from several species of plants. Tragacanth is used as a soothing and anti-cough agent in the common cold medication. There are two types of active ingredients in tragacanth: 1-Tragacanthin: It is a glucuronic acid that binds to several molecules of arabinose glucose.2-Basorine: It is insoluble in water especially cold water and contains galacturonic acid. These are galactose and xylose sugars (Bagheri et al, 2015). Therefore, due to the strong interaction of these natural compounds with enzymatically conserved regions and specific functionality, these compounds can be considered as effective antiviral drugs due to their natural origin and less likely to produce adverse effects if they enhance the interaction. During chemical processes and microbial biodegradations can be suitable substitutes for synthetic and chemical drugs that have side effects. 


\section{Conclusion}

Based on the results of the present study, it can be concluded that the compounds investigated can interact with important amino acids in the enzyme flap to inhibit the new coronavirus protease enzyme. Among these secondary metabolite, Curcumin, The secondary metabolite of turmeric has the strongest interaction with the protease enzyme COVID_19.

\section{Reference}

Baell, J. B. (2016). Feeling nature's PAINS: natural products, natural product drugs, and pan assay interference compounds (PAINS). Journal of natural products, 79(3), 616-628.

Bagheri, S. M., Keyhani, L., Heydari, M., \& Dashti-R, M. H. (2015). Antinociceptive activity of Astragalus gummifer gum (gum tragacanth) through the adrenergic system: A in vivo study in mice. Journal of Ayurveda and integrative medicine, 6(1), 19.

Chen, Y., Liu, Q., \& Guo, D. (2020). Emerging coronaviruses: genome structure, replication, and pathogenesis. Journal of medical virology.

Da Silva-Ferrada, E., Ribeiro-Rodrigues, T. M., Rodríguez, M. S., \& Girão, H. (2016). Proteostasis and SUMO in the heart. The international journal of biochemistry \& cell biology, 79, 443450.

Grinter, S. Z., \& Zou, X. (2014). Challenges, applications, and recent advances of protein-ligand docking in structure-based drug design. Molecules, 19(7), 10150-10176.

Li, Y., Zhang, J., Wang, N., Li, H., Shi, Y., Guo, G., . . Zou, Q. (2020). Therapeutic Drugs Targeting 2019-nCoV Main Protease by High-Throughput Screening. bioRxiv.

Liu, X., Zhang, B., Jin, Z., Yang, H., \& Rao, Z. (2020). The Crytal Structure of 2019-NCoV Main Protease in Complex with an Inhibitor N3. RCSB Protein Data Bank.

Lu, X., Samuelson, D. R., Rasco, B. A., \& Konkel, M. E. (2012). Antimicrobial effect of diallyl sulphide on Campylobacter jejuni biofilms. Journal of antimicrobial chemotherapy, 67(8), 1915-1926.

Maleki-Dizaji, N., Nazemiyeh, H., Maddah, N., Mehmani, F., \& Garjani, A. (2008). Screening of extracts and fractions from aerial parts of Stachys schtschegleevii Sosn. for anti-inflammatory activities. Pakistan journal of pharmaceutical sciences, 21(4).

Menon, V. P., \& Sudheer, A. R. (2007). Antioxidant and anti-inflammatory properties of curcumin The molecular targets and therapeutic uses of curcumin in health and disease (pp. 105-125): Springer.

Mukesh, B., \& Rakesh, K. (2011). Review on Molecular docking. Ijrap, 2(6), 1746-1751.

shaghaghi, neda (2020): Molecular Docking Study of Novel COVID-19 Protease with Low Risk Terpenoides Compounds of Plants. ChemRxiv. Preprint. https://doi.org/10.26434/chemrxiv.11935722.v1

Sricharoen, P., Lamaiphan, N., Patthawaro, P., Limchoowong, N., Techawongstien, S., \& Chanthai, S. (2017). Phytochemicals in Capsicum oleoresin from different varieties of hot chilli peppers with their antidiabetic and antioxidant activities due to some phenolic compounds. Ultrasonics sonochemistry, 38, 629-639.

Venugopala, K. N., Rashmi, V., \& Odhav, B. (2013). Review on natural coumarin lead compounds for their pharmacological activity. BioMed research international, 2013.

Vutakuri, N., \& Somara, S. (2018). Natural and herbal medicine for breast cancer using Elettaria cardamomum (L.) Maton. IJHM, 6, 91-96. 
Wang, M., Cao, R., Zhang, L., Yang, X., Liu, J., Xu, M., . . Xiao, G. (2020). Remdesivir and chloroquine effectively inhibit the recently emerged novel coronavirus (2019-nCoV) in vitro. Cell research, 1-3.

Xu, Z., Peng, C., Shi, Y., Zhu, Z., Mu, K., Wang, X., \& Zhu, W. (2020). Nelfinavir was predicted to be a potential inhibitor of 2019-nCov main protease by an integrative approach combining homology modelling, molecular docking and binding free energy calculation. bioRxiv. 